\title{
Health Promoting Behaviors and Self-efficacy of Physical Activity During Pregnancy: An Interventional Study
}

\author{
Leila Ghahremani $^{1 *}$, Monireh Alipoor ${ }^{1}$, Sedighe Amoee ${ }^{2}$, Sareh Keshavarzi ${ }^{3}$
}

\begin{abstract}
Objectives: Health-promoting behaviors during pregnancy are those that encourage or improve health-related quality of life, both maternal and foetal. They also decrease risk factors. The present study aims to investigate the effect of health education on healthpromoting behaviors in pregnant women in Mahshahr, southern Iran

Materials and Methods: In this experimental study, 78 pregnant women were selected using multi-stage sampling and were randomly divided into 2 groups each including 39 subjects. The intervention group learned physical activity and health behaviors based on the constructs of self-efficacy through 6 sessions. However, no interventions were performed for the control group. The data were collected using a questionnaire containing demographic information, health-promoting lifestyle, and Exercise Self-Efficacy Scale (ESES) before and one month after the intervention. Then, the data were analyzed using t test, chi-square test, and regression analysis. Results: After the intervention, the mean score of health-promoting behaviors, subscale and physical activity self-efficacy increased in the intervention group, which was significantly different from the control group $(P<0.001)$. Moreover, the results revealed that all the subscale Health Promoting Lifestyle Profile (HPLP) predictive health-promoting behaviors, with the highest predictive power were related to physical activity $(\beta=1.045, P<0.001)$.

Conclusion: The results of current study supported the effectiveness of training and revealed that training based on self-efficacy theory led to an increase in the mean score of health-promoting behaviors, particularly physical activity and motivational skills (selfcontrol and feeling of self-efficiency). Thus, by creating and maintaining regular health-promoting behaviors, maternal and fetal health and well-being can be guaranteed.

Keywords: Pregnancy, Health-promoting behaviors, Self-efficacy
\end{abstract}

\section{Introduction}

Maintaining a health-promoting lifestyle is defined as controlling certain behaviors and selecting appropriate behaviors in the daily life for one's own health (1). Healthpromotion behavior is a multifaceted model of perception, self-initiated action or practice (2). It is a response to World Health Organization's (WHO's) goal of "health for all” (3). According to Pender, health promoting lifestyle behaviors include nutrition, exercise, stress management, health responsibility, spiritual improvement, and interpersonal relations (4).

During pregnancy, health-promoting lifestyle leads to a reduction in risk factors and an improvement of infant's health (3). Nowadays, the mortality of pregnant women is one of the key indices of health in all countries. This has both direct and indirect impacts on pregnancy outcomes. The health of pregnant women - as a vulnerable group is of particular importance in the healthcare systems (5). In fact, a large number of physiological, psychological, and social changes occur during pregnancy. The mother's adjustment to these changes is highly important (6). Rubin stated that it is necessary for pregnant women to acquire 4 maternal duties, the most important of which is seeking for safety. Therefore, the following health-promoting behaviors are essential for giving birth to a healthy infant (2).

Although a great body of evidence exists in respect of the benefits of health promoting behaviors, getting people to adopt a healthy lifestyle is challenging (7). Unfortunately, many women are against the application of healthy behaviors during pregnancy. For example there is a decrease in the level of physical activity as pregnancy progresses (8).

Physical activity on pregnancy has many positive effects on the health of the mother and foetus (9). These include better health-related quality of life (10), reduction of stress and depressive symptoms (11), less delivery pain, lower rate of cesarean delivery, lower risk of obesity, selfefficacy, and better body image (12). Overall, pregnant women faced the challenge of continuing physical activity during pregnancy (13).

Self-efficacy has been defined as an individual's perceived belief in having the ability to benefit from one's personal sources of motivation and organization and acts to reach a specific goal (14). Self-efficacy is a strong predictor of health behaviors, and also initiation and maintenance of exercise during pregnancy (13). Bandura indicated that theory of self-efficacy provides a convincing explanation

Received 13 January 2017, Accepted 25 May 2017, Available online 30 June 2017

${ }^{1}$ Department of Health Education and Promotion, School of Health, Shiraz University of Medical Sciences, Shiraz, Iran. ${ }^{2}$ Department of Gynecology and Obstetrics, School of Medicine, Shiraz University of Medical Sciences, Shiraz, Iran. ${ }^{3}$ Department of Epidemiology, School of Health, Shiraz University of Medical Sciences, Shiraz, Iran.

*Corresponding Author: Leila Ghahremani, Tel: +98 9177923542, Email: ghahramanl@sums.ac.ir 
of the reasons for behavior change (15). In fact, there exists an underlying structure for better performance (16).

Pregnancy provides an opportunity for behavioral interventions $(17,18)$ and improvement of women's and their children's health $(19,20)$. Minimizing concerns related to behavior change is the best motivation for pregnant women (21). The present study has been conducted to evaluate the effectiveness of educational programs on health-promotion behaviors and self-efficacy of physical activity during pregnancy.

\section{Materials and Methods}

This experimental study included 78 pregnant women referring to healthcare centers in Mahshahr city, located in the southern of Iran. The participants were selected through multi-stage sampling. At first, 8 out of the 16 health centers were selected using cluster sampling. Then, they were randomly divided into an intervention and a control group. In these centers, the individuals who willing to cooperate were enrolled into the research.

The sample size was calculated based on previous studies, assuming a mean difference of 5 between 2 groups. Considering $\alpha=0.05$ and power $(1-\beta)$ of $80 \%$, a 78 -subject sample size was determined for this study (39 pregnant women in each group) (22).

The inclusion criteria were gestational age of 14-24 weeks, having at least middle school degree, not having high-risk pregnancy, and being willing to take part in the study. The exclusion criteria were being absent for more than 1 educational session and not being available for completing the questionnaire at the second stage of the study.

The data was collected using 3 questionnaires. 1) The socio-demographic questionnaire included information about age, marriage age, education, number of pregnancies, pregnancy trimester, employment statues, income level, daily exercise, anxiety during pregnancy, and history of diseases before and during pregnancy. 2) The Persian version of Health Promoting Lifestyle Profile II (HPLP-II). This questionnaire consists of 52 questions in 6 subscale, namely nutrition, physical activity, health responsibility, stress management, interpersonal relations, and spiritual growth. All items of health-promoting behaviors are scored on the basis of a 4-point Likert scale ranging from 1 to 4 . Overall, HPLP-II scores mark interval between 52 to 208. The reliability and validity of HPLPII was 0.922 for the whole scale and subscales were range from 0.702 to 0.904 (23). According to Aghamolaei and Ghanbarnejad, alpha coefficient reliability was 0.92 for the whole scale and 0.71-0.86 for the subscale (24). 3) Exercise Self-Efficacy Scale (ESES), designed by Kroll et al. This questionnaire contains 10 items, which were scored based on a 4-point Likert scale. The reliability of this scale was approved by alpha coefficient reliability of 0.926 (25).

Considering the study objectives and the results of pretest, educational intervention based the theory of selfefficacy was conducted for the intervention group in 6 training sessions. Educational content included anatomic and physiological changes, importance of physical activity, relaxation techniques and interpersonal, problem-solving and self-control skills, and matter relating to nutrition and spiritual growth. The subjects were presented with interactive speech and group discussion using video projector, Power Point, and booklets to enhance learning, while the pregnant women in control group did not receive training.

The data was collected through questionnaires filled out before (pre-test) and 1 month after (post-test) the intervention by both study groups. After all, the data was entered into the SPSS ${ }^{\circledR}$ statistics for Windows ${ }^{\circledR}$ and were analyzed using descriptive and inferential statistics, and regression analysis.

\section{Results}

Distribution of the pregnant women's demographic information has been presented in Table 1. Their mean age was $26.79 \pm 5.26$ years in the intervention group and $27.17 \pm 6.10$ years in the control group. In addition, $80 \%$ of the participants had no history of diseases prior to pregnancy. Accordingly, no significant difference was found between the 2 groups about the demographic characteristics.

The results of the study revealed, the 2 groups were significantly difference concerning the mean score of physical activity, health responsibility, and stress management after the intervention. However, no significant different was found between 2 groups before the intervention (Table 2).

Based on the results, the mean of health-promoting behaviors increased in the intervention group, but decreased in the control group after the intervention, and the difference was statistically significant $(P<0.001)$ (Table 2).

Additionally, a significant difference was found in the intervention group's average scores of health responsibility $(P<0.006)$, physical activity $(P<0.001)$, nutrition $(P<0.001)$, and stress management $(P<0.001)$, and total score of health-promoting behaviors $(P<0.001)$. However, no significant difference was observed in this regard in the control group (Table 2).

Considering interpersonal relations and spiritual growth, the results showed a significant difference between 2 groups before and after the intervention while no significant difference was found between the 2 groups regarding nutritional behaviors (Table 2 ).

Moreover, independent $t$ test was employed to assess the effect of training on the mean score of physical activity self-efficacy. The results showed a significant difference in this regard in the 2 groups after the intervention $(P<0.001)$, but not before that $(P=0.588)$ (Table 3$)$.

In regression model with Enter method, mean difference scores subscale Health-Promoting Lifestyle Profile II (HPLP-II), as predictive variable, and mean difference scores HPLP, as dependent variable, were investigated. Demographic factors and baseline levels were controlled. Results in Table 4 showed that changes in 
Table 1. Distribution of the Socio-Demographic Characteristics of the Pregnant Women

\begin{tabular}{|c|c|c|c|}
\hline Characteristics & Intervention Group & Control Group & $P$ Value \\
\hline Age, $y$; mean $\pm S D(\min -\max )$ & $26.79 \pm 5.26(19-43)$ & $27.17 \pm 6.10(18-43)$ & $0.767^{\mathrm{a}}$ \\
\hline Pregnancy age, wk; mean $\pm S D$ (min- max) & $19.61 \pm 3.21(14-24)$ & $18.53 \pm 3.50(14-24)$ & $0.162^{\mathrm{a}}$ \\
\hline No. of pregnancy, mean $\pm S D(\min -\max )$ & $1.46 \pm 0.78(1-4)$ & $1.56 \pm 0.99(1-6)$ & $0.615^{\mathrm{a}}$ \\
\hline Age marriage, $y$; mean $\pm S D(\min -\max )$ & $22.07 \pm 3.23(13-28)$ & $21.64 \pm 4.03(10-32)$ & $0.603^{\mathrm{a}}$ \\
\hline Educational state, No. (\%) & & & $0.352^{b}$ \\
\hline Diploma or lower & $22(56.4 \%)$ & $26(66.7 \%)$ & \\
\hline College or more & $17(43.6 \%)$ & $13(33.3 \%)$ & \\
\hline Occupational status, No. (\%) & & & $0.761^{\mathrm{b}}$ \\
\hline Unemployed & $32(82.1 \%)$ & $33(84.6 \%)$ & \\
\hline Employed & $7(17.9 \%)$ & $6(15.4 \%)$ & \\
\hline Income, No. (\%) & & & $0.456^{b}$ \\
\hline Very good - good & $13(33.3 \%)$ & $10(25.6 \%)$ & \\
\hline Average-bad & $26(66.7 \%)$ & $29(74.4 \%)$ & \\
\hline Selected type of childbirth, No. (\%) & & & $0.591^{b}$ \\
\hline Natural childbirth & $29(74.4 \%)$ & $31(79.5 \%)$ & \\
\hline Cesarean section & $10(25.6 \%)$ & $8(20.5 \%)$ & \\
\hline
\end{tabular}

a Independent samples test.

${ }^{\mathrm{b}}$ Chi-square.

Table 2. Distribution of HPLPII Scale Average Score in the 2 Groups Before and After the Intervention

\begin{tabular}{|c|c|c|c|c|c|c|c|c|}
\hline Subscale & $\begin{array}{l}\text { Range of } \\
\text { Possible } \\
\text { Scores }\end{array}$ & Group (n) & $\begin{array}{l}\text { Before the } \\
\text { Intervention } \\
\text { Mean } \pm \text { SD }\end{array}$ & $\begin{array}{l}\text { After the } \\
\text { Intervention } \\
\text { Mean } \pm \text { SD }\end{array}$ & $\boldsymbol{P}^{\mathrm{a} *}$ & $P^{\mathrm{b} * *}$ & $\mathbf{P}^{\mathrm{b} * * *}$ & $\mathbf{P}^{\mathrm{b} * * * *}$ \\
\hline \multirow{2}{*}{ Physical activity } & \multirow{2}{*}{$8-32$} & Intervention (39) & $12.46 \pm 2.83$ & $19.02 \pm 3.60$ & $<0.001$ & \multirow{2}{*}{0.350} & \multirow{2}{*}{$<0.001$} & \multirow{2}{*}{$<0.001$} \\
\hline & & Control (39) & $13.12 \pm 3.39$ & $12.84 \pm 3.42$ & 0.456 & & & \\
\hline \multirow{2}{*}{ Health responsibility } & \multirow{2}{*}{$9-36$} & Intervention (39) & $28.58 \pm 3.95$ & $29.92 \pm 4.06$ & 0.006 & \multirow{2}{*}{0.050} & \multirow{2}{*}{0.001} & \multirow{2}{*}{0.068} \\
\hline & & Control (39) & $26.58 \pm 4.85$ & $26.56 \pm 4.39$ & 0.931 & & & \\
\hline \multirow{2}{*}{ Stress management } & \multirow{2}{*}{$8-32$} & Intervention (39) & $18.48 \pm 3.44$ & $22.66 \pm 3.26$ & $<0.001$ & \multirow{2}{*}{0.736} & \multirow{2}{*}{$<0.001$} & \multirow{2}{*}{$<0.001$} \\
\hline & & Control (39) & $18.23 \pm 3.24$ & $17.82 \pm 3.53$ & 0.316 & & & \\
\hline \multirow{2}{*}{$\begin{array}{l}\text { Interpersonal } \\
\text { relations }\end{array}$} & \multirow{2}{*}{$9-36$} & Intervention (39) & $28.84 \pm 4.23$ & $29.43 \pm 4.41$ & 0.364 & \multirow{2}{*}{0.017} & \multirow{2}{*}{0.002} & \multirow{2}{*}{0.354} \\
\hline & & Control (39) & $26.35 \pm 4.70$ & $26.17 \pm 4.33$ & 0.718 & & & \\
\hline \multirow{2}{*}{ Spiritual growth } & \multirow{2}{*}{$9-36$} & Intervention (39) & $29.10 \pm 4.42$ & $29.89 \pm 4.80$ & 0.136 & \multirow{2}{*}{0.016} & \multirow{2}{*}{0.006} & \multirow{2}{*}{0.354} \\
\hline & & Control (39) & $26.71 \pm 4.05$ & $26.84 \pm 4.71$ & 0.658 & & & \\
\hline \multirow{2}{*}{ Nutrition } & \multirow{2}{*}{$9-36$} & Intervention (39) & $26.05 \pm 4.24$ & $27.92 \pm 3.91$ & 0.001 & \multirow{2}{*}{0.787} & \multirow{2}{*}{0.124} & \multirow{2}{*}{0.036} \\
\hline & & Control (39) & $26.30 \pm 4.11$ & $26.43 \pm 4.50$ & 0.841 & & & \\
\hline \multirow{2}{*}{ Total } & \multirow{2}{*}{$52-208$} & Intervention (39) & $140.33 \pm 14.18$ & $155.51 \pm 17.10$ & $<0.001$ & \multirow{2}{*}{0.126} & \multirow{2}{*}{$<0.001$} & \multirow{2}{*}{$<0.001$} \\
\hline & & Control (39) & $134.46 \pm 19.01$ & $133.79 \pm 19.19$ & 0.706 & & & \\
\hline
\end{tabular}

Abbreviation: HPLP-II, Health Promoting Lifestyle Profile II; SD, standard deviation.

a Paired $t$ test.

${ }^{\mathrm{b}}$ Independent samples test.

* Comparison of mean scores in the intervention and control groups before and after the intervention.

** Comparison of mean scores between the intervention and control groups before the intervention.

$* * *$ Comparison of mean scores between the intervention and control groups after the intervention.

$* * * *$ Comparison of mean difference scores in the intervention and control groups before and after the intervention.

health-promoting behaviors of the intervention group is explained $99 \%$ by subscale HPLP $\left(\mathrm{R}^{2}=0.999\right)$. The results revealed that all the subscale HPLP predictive healthpromoting behaviors, with the highest predictive power were related to physical activity $(\beta=1.045, P<0.001)$ followed by nutrition $(\beta=1.062, P<0.001)$ (Table 4$)$.

\section{Discussion}

The study results indicated a significant increase in the mean score of HPLP in the intervention group. However, a significant reduction was observed in the control group.
In the same line, the results of a quasi-experimental study performed by Sen and Sirin indicated that the average score of HPLP considerably increased in the experimental group (26). The study conducted by Mauriello et al revealed that programme intervention related to higher health, learned new information and increase in intention to make behavioral changes (27). Ko et al and Hui et al confirmed these findings $(28,29)$. Hence, it can be concluded that sufficient and efficient training during pregnancy can increase pregnant women's motivation for doing healthy behaviors. 
Table 3. Distribution of Physical Activity Self-efficacy Average Scores in the 2 Groups Before and After the Intervention

\begin{tabular}{lcccc}
\hline Scores & Intervention group (Mean \pm SD) & Control group (Mean \pm SD) & $\boldsymbol{t}$ & 0.588 \\
\hline Before the Intervention & $25.35 \pm 7.49$ & $24.38 \pm 8.30$ & 0.588 \\
After the Intervention & $31.20 \pm 5.98$ & $24.00 \pm 7.87$ & 4.550 & 0.001 \\
\hline
\end{tabular}

a Independent samples test.

Table 4. Regression Analyses of the Effect of the Subscale HPLP on Health-Promoting Behaviors

\begin{tabular}{|c|c|c|c|c|c|}
\hline Subscale & Standardized $\beta^{\text {a }}$ & SEB ${ }^{b}$ & $\boldsymbol{\beta}^{c}$ & $t$ & $P$ Value \\
\hline Physical activity & 1.045 & 0.031 & 0.339 & 33.469 & $<0.001$ \\
\hline Nutrition & 1.023 & 0.031 & 0.280 & 32.884 & $<0.001$ \\
\hline Health responsibility & 0.838 & 0.038 & 0.208 & 21.989 & $<0.001$ \\
\hline Stress management & 0.967 & 0.039 & 0.248 & 24.731 & $<0.001$ \\
\hline Interpersonal relations & 0.995 & 0.032 & 0.264 & 30.921 & $<0.001$ \\
\hline Spiritual growth & 0.957 & 0.045 & 0.207 & 21.155 & $<0.001$ \\
\hline
\end{tabular}

Abbreviation: HPLP, Health Promoting Lifestyle Profile.

${ }^{a} \beta$-coefficients; ${ }^{\text {b }}$ SEs of the $\beta$ coefficients; ${ }^{\mathrm{c}}$ Standardized beta coefficients for the regression model.

The results showed that the mean score of physical activity significantly increased in the intervention group, but remained unchanged in the control group. In addition, a significant difference was found between the 2 groups in this respect after the intervention. Hui et al also reported that lifestyle intervention during pregnancy resulted in an increase in physical activity (29). In contrast, Poston et al conducted a study in 2013 and did not reveal any change exercise between the 2 groups (30). This can be attributed to the fact that while advising pregnant women to undertake physical activities, their conditions, pregnancy disorders, physical activity level, and motivational factors have to be taken into account and proper strategies have to be proposed.

According to Canadian guideline, all healthy pregnant women are advised to perform 30 minutes of physical activities a day for 3 to 4 days a week (31).

The finding of this study highlighted that stress management significantly increased among pregnant women in the intervention group compared to the control group after the intervention. Various studies have also demonstrated that the stress management program significantly reduces stress and promotes health in pregnant women (32). Urech et al reported that active relaxation techniques, especially guided imagery, are much effective in enhancing levels of relaxation and reduction of stress in pregnant women (33). Health behaviors may increase the ability of pregnant women to successfully adapt to stress and reduce the negative impact of stress on their physical, mental, and social functions (34).

Health responsibility and interpersonal relations have positive relationship with learning problem-solving skills, self-care, and search for health information (1). In this study, the high value of health responsibility, interpersonal relations and spiritual growth the results of independent in 2 groups before the intervention implied that pregnant women have higher motivation for taking in healthy behaviors. These findings were similar to those obtained by Gharaibeh et al and Lin et al $(2,35)$.

In our study, no significant difference was found between the 2 groups in average score of nutritional behaviors before and after training. Nonetheless, a significant improvement was revealed in the intervention group's nutritional behaviors before and after the intervention, while this was not the case in the control group. In a study, Wilkinson and McIntyre indicated that the quality of eating diet did not change significantly between the 2 groups (36). Furthermore, Claesson et al revealed that physical activity led to an improvement in mental and physical health in obese pregnant women, but did not prevent weight change (37).

Based on the above-mentioned findings, the insignificant difference can be attributed to pregnant women paying more attention to quality of nutrition and having higher motivation to obtain information in this area. Likewise, the control group might have received nutritional information in their routine pregnancy care.

The study results showed a significant difference in the 2 groups' average scores of self-efficacy after the intervention. However, Sen and Sirin indicated no significant difference in 2 groups' average scores of selfefficacy (26). Gaston et al reported a considerable increase in self-efficacy and action plans physical activity in pregnant women who received an educational message (13). Similarly, Bauer et al indicated a positive correlation between self-efficacy and physical activity (38). Lin et al also reported a significantly positive relationship between self-efficacy and health promoting lifestyles (2).

Generally, self-efficacy is not related to individuals' ability to conduct a particular behavior or obtain a desirable outcome;rather, it refers to their judgment and investigation of the belief about what they can do for maintaining or improving their health (39). 


\section{Conclusion}

The results of the current study indicated that all the dimensions of health promoting behaviors were correlated to each other. Yet, the coefficients were stronger in some dimensions such as physical activity, playing a more critical role in improvement of maternal and foetal quality of life. Furthermore, by using techniques for increasing self-efficacy, effective measures can be taken towards improvement of such behaviors.

\section{Limitations}

1) Although this sample size was calculated based on formula, for more realistic results, there is a needs to carry out studies with larger samples.

2) The educational program and follow-up periods were short. The authors suggest that they should be followed up until 6 months after the educational program.

\section{Ethical Issues}

The ethics committees of Shiraz University of Medical Sciences (SUMS) approved the study (No. 94-7533). Also, the study was listed in the Iranian Registry of Clinical Trials website (Identifier: IRCT2015073015015N12). Considering ethical issues, written informed consents were obtained from all the participants.

\section{Conflict of Interests}

None.

\section{Financial Support}

This study was financially supported by Vice-chancellor of Shiraz University of Medical Sciences, Shiraz, Iran (grant No. 94-7533).

\section{Acknowledgements}

This study was extracted from Monireh Alipoor M.Sc thesis in Health Education and Health Promotion and supported by the Research Vice-Chancellor of Shiraz University of Medical Sciences in Shiraz, Iran Grant No.94-7533. Hereby, the authors would like to thank all the participants who helped us to conduct this study.

\section{References}

1. Gokyildiz S, Alan S, Elmas E, Bostanci A, Kucuk E. Healthpromoting lifestyle behaviours in pregnant women in Turkey. Inte J Nurs Pract. 2014;20:390-397. doi:10.1111/ ijn.12187.

2. Lin Y, Tsai E, Chan T, Chou F, Lin Y. Health promoting lifestyles and related factors in pregnant women. Chang Gung Medical J. 2009;32:650-661.

3. Kavlak O, Atan SU, Sirin A, Sen E, Guneri SE, Dag HY. Pregnant Turkish women with low income: their anxiety, health-promoting lifestyles, and related factors. Inte J Nurs Pract. 2013;19:507-515. doi:10.1111/ijn.12093

4. Nazari M, Farmani S, Kaveh MH, Ghaem H. The effectiveness of lifestyle educational program in health promoting behaviors and menopausal symptoms in 45-60-year-old women in Marvdasht, Iran. Glob J Health Sci. 2016;8(10):1-9. doi:10.5539/gjhs.v8n10p34.
5. Mahmoodi Z, Karimlou M, Sajjadi H, Dejman M, Vameghi M. Development of mother's lifestyle scale during pregnancy with an approach to social determinants of health. Glob J Health Sci. 2013;5:208-219.

6. Mparmpakas D, Goumenou A, Zachariades E, Pados G, Gidron Y, Karteris E. Immune system function, stress, exercise and nutrition profile can affect pregnancy outcome: Lessons from a Mediterranean cohort. Exp Ther Med. 2013;5:411-418. doi:10.3892/etm.2012.849

7. Edvardsson K, Ivarsson A, Eurenius E, et al. Giving offspring a healthy start: parents' experiences of health promotion and lifestyle change during pregnancy and early parenthood. BMC Public Health. 2011;11:936. doi:10.1186/1471-2458-11-936

8. Leiferman J, Sinatra E, Huberty J. Pregnant women's perceptions of patient-provider communication for health behavior change during pregnancy. Open J Obstet Gynecol. 2014;4(11):672-684. doi:10.4236/ojog.2014.411094

9. Grace SL, Williams A, Stewart DE, Franche R-L. Healthpromoting behaviors through pregnancy, maternity leave, and return to work: effects of role spillover and other correlates. Women Health. 2006;43:51-72. doi:10.1300/ J013v43n02_04

10. Kolu P, Raitanen J, Luoto R. Physical activity and healthrelated quality of life during pregnancy: a secondary analysis of a cluster-randomised trial. Matern Child Health J. 2014;18:2098-2105. doi:10.1007/s10995-014-1457-4.

11. Vernon MM, Young-Hyman D, Looney SW. Maternal stress, physical activity, and body mass index during new mothers' first year postpartum. Women Health 2010;50: 544-562. doi:10.1080/03630242.2010.516692.

12. DiNallo JM. Examining the Moderating Influence of Motherhood Status on the Determinants of Exercise Motivation and Behavior in Pregnancy. The Pennsylvania State University; 2011.

13. Gaston A, Cramp A, Prapavessis H. Enhancing self-efficacy and exercise readiness in pregnant women. Psychol Sport Exerc. 2012;13:550-7 doi:10.1016/j.psychsport.2012.03.001.

14. Fisher K, Kridli SAO. The role of motivation and selfefficacy on the practice of health promotion behaviours in the overweight and obese middle-aged American women. Inte J Nurs Pract. 2014;20:327-35. doi:10.1111/ijn.12155.

15. Schunk DH, Pajares F. Self-Efficacy Beliefs. In: McGaw PPB, ed. International Encyclopedia of Education. 3rd ed. Oxford: Elsevier; 2010:668-672. doi:10.1016/B978-0-08044894-7.00620-5.

16. Ghahremani L, Harami ZK, Kaveh MH, Keshavarzi S. Investigation of the role of training health volunteers in promoting Pap Smear test use among Iranian women based on the protection motivation theory. Asian Pac J Cancer Prev. 2016;117(12):5133-5138. doi:10.22034/ APJCP.2016.17.12.5133.

17. Weir Z, Bush J, Robson SC, McParlin C, Rankin J, Bell R. Physical activity in pregnancy: a qualitative study of the beliefs of overweight and obese pregnant women. BMC Pregnancy Childbirth. 2010;10:18. doi:10.1186/1471-239310-18

18. Ghasemi S, Nazari M, Vafaei H, Fararouei M. The impact of educational intervention based on the theory of planned behavior in choosing delivery mode in primigravida pregnant women. Int J Womens Health Reprod Sci. 2017;5(1):47-54. doi:10.15296/ijwhr.2017.09.

19. Prochaska JM, Mauriello L, Dyment S, Gökbayrak 
S. Designing a health behavior change program for dissemination to underserved pregnant women. Public Health Nurs. 2011;28:548-55. doi:10.1111/j.15251446.2011.00959.x.

20. Ferguson S, Davis D, Browne J. Does antenatal education affect labour and birth? A structured review of the literature. Women Birth. 2013;26:e5-e8. doi:10.1016/j. wombi.2012.09.003

21. Campbell F, Johnson M, Messina J, Guillaume L, Goyder E. Behavioural interventions for weight management in pregnancy: a systematic review of quantitative and qualitative data. BMC Public Health. 2011;11:491. doi:10.1186/1471-2458-11-491.

22. Jahdi F, Montazeri A, Balouchi M, Behboodi Moghadam $Z$. The impact of group prenatal care on pregnant women empowerment. Journal of the Iranian Institute for Health Sciences Research. 2014;13:229-34. [Persian].

23. Walker SN, Sechrist KR, Pender NJ. The healthpromoting lifestyle profile: development and psychometric characteristics. Nurs Res. 1987;36:76-81.

24. Aghamolaei T, Ghanbarnejad A. Validity and reliablity of the Persian health-promoting lifestyle profile II questionnaire. Health Behaviors of Adolescents. 2015;5:358-65.

25. Kroll T, Kehn M, Ho P-S, Groah S. The SCI exercise selfefficacy scale (ESES): development and psychometric properties. Int J Behav Nutr Phys Act. 2007;4:34. doi:10.1186/1479-5868-4-34.

26. Sen E, Sirin A. Healthy lifestyle behaviors and self-efficacy: the effect of education. Anthropologist Journal. 2015;21: 89-97.

27. Mauriello L, Dyment S, Prochaska J, Gagliardi A, WeingradSmith J. Acceptability and feasibility of a multiple-behavior, computer-tailored intervention for underserved pregnant women. J Midwifery Womens Health. 2011;56:75-80. doi:10.1111/j.1542-2011.2010.00007.x.

28. Ko JM, Lee JK. Effects of a coaching program on comprehensive lifestyle modification for women with gestational diabetes mellitus. J Korean Acad Nurs. 2014;44(6):672-81. doi:10.4040/jkan.2014.44.6.672.

29. Hui A, Back L, Ludwig S, et al. Lifestyle intervention on diet and exercise reduced excessive gestational weight gain in pregnant women under a randomised controlled trial. BJOG. 2012;119:70-77. doi:10.1111/j.1471- 0528.2011.03184.x.

30. Poston L, Briley AL, Barr S, et al. Developing a complex intervention for diet and activity behaviour change in obese pregnant women (the UPBEAT trial); assessment of behavioural change and process evaluation in a pilot randomised controlled trial. BMC Pregnancy Childbirth. 2013;13:148. doi:10.1186/1471-2393-13-148.

31. Gaston A, Prapavessis H. Using a combined protection motivation theory and health action process approach intervention to promote exercise during pregnancy. J Behav Med. 2014;37:173-84. doi:10.1007/s10865-012-9477-2.

32. Tragea C, Chrousos GP, Alexopoulos EC, Darviri C. A randomized controlled trial of the effects of a stress management programme during pregnancy. Complement Ther Med. 2014;22:203-211 doi:10.1016/j.ctim.2014.01.006.

33. Urech C, Fink NS, Hoesli I, Wilhelm FH, Bitzer J, Alder J. Effects of relaxation on psychobiological wellbeing during pregnancy: a randomized controlled trial. Psychoneuroendocrinology. 2010;35:1348-55. doi:10.1016/j.psyneuen.2010.03.008.

34. Miller KG. Impact of health behaviors on prenatal maternal stress [Master Thesis]. Long Beach: California State University; 2014.

35. Gharaibeh $\mathrm{M}, \mathrm{Al}-\mathrm{Ma}$ 'aitah $\mathrm{R}, \mathrm{Al}$ Jada N. Lifestyle practices of Jordanian pregnant women. Int Nurs Rev. 2005;52:92100. doi:10.1111/j.1466-7657.2005.00257.x.

36. Wilkinson SA, McIntyre HD. Evaluation of the'healthy start to pregnancy'early antenatal health promotion workshop: a randomized controlled trial. BMC Pregnancy Childbirth. 2012;12:131. doi:10.1186/1471-2393-12-131.

37. Claesson I-M, Klein S, Sydsjö G, Josefsson A. Physical activity and psychological well-being in obese pregnant and postpartum women attending a weight-gain restriction programme. Midwifery. 2014;30:11-16. doi:10.1016/j. midw.2012.11.006.

38. Bauer PW, Pivarnik JM, Feltz DL, Paneth N, Womack CJ. Relationship of past-pregnancy physical activity and selfefficacy with current physical activity and postpartum weight retention. Am J Lifestyle Med. 2014;8:68-73. doi:10.1177/1559827613498061

39. Gallagher MW, Ramachandran VS. Self-efficacy. Encyclopedia of Human Behavior. 2nd ed. San Diego: Academic Press; 2012:314-320.

Copyright (C) 2017 The Author (s);This is an open-access article distributed under the terms of the Creative Commons Attribution License (http://creativecommons.org/licenses/by/4.0), which permits unrestricted use, distribution, and reproduction in any medium, provided the original work is properly cited. 